\title{
De frente para o mar: Os geossítios costeiros do Brasil
}

\author{
In front of the sea: Coastal geosites of Brazil.
}

$\mathrm{Meira}^{1}$, S. A.

suediomeira@gmail.com

\begin{abstract}
Resumo
A Zona Costeira Brasileira (ZCB) é uma estreita faixa que se estende paralelamente ao litoral, composta por 395 municípios é uma área historicamente favorecida pela urbanização e elevada biodiversidade e geodiversidade. Diante disso o presente artigo discute os elementos da geodiversidade presente na ZCB que adquirem caráter excepcional e são classificados como geossítios pela Comissão Brasileira de Sítios Geológicos e Paleobiológicos (SIGEP). A metodologia utilizada é baseada em busca, tratamento e discussão de dados oriundos de levantamento bibliográfico. Conclui-se a importância e diversidade dos geossítios presentes na ZCB. Nos três volumes publicados pela SIGEP estão presentes 21 geossítios costeiros $(18,1 \%$ do total de sítios publicados), os quais pertencerem a oito categorias temáticas distintas. Doze geossítios estão inseridos em áreas com algum regime de proteção legal $(57,14 \%$ do total), porém, o restante carece de medidas específicas que promovam a proteção desses ambientes relevantes para o entendimento da evolução geológica do Brasil.
\end{abstract}

Palavras-chave: Patrimônio Geológico. SIGEP.

Geodiversidade.

\begin{abstract}
The Brazilian Coast Zone is a thin ribbon going parallel to the coastline, composed by 395 counties, it is historically favored by urbanization and presents high biodiversity and geodiversity. In face of that reality, the presente paper discuss the geodiversity elements present in that zone with exceptional character and classified as geosites by the Brazilian Geological and Paleobiological Geosites Commission. The used methodology is based on the bibliographical data research, valorization and discussion. We conclude the importance and diversity of the coast zone geosites. In the three volumes published by the commission, 21 coastal geosites are present $(18,1 \%$ of all published geosites), which belong to eight distinct thematic categories. Twelve geosites are inserted in areas with some law protection regime $(57,14 \%$ of the total), however, the rest of them needs specific measures that promote the protection of these relevant environments for the understanding of the Brazilian geological evolution.
\end{abstract}

Keywords: Geoheritage. SIGEP. Geodiversity.

\section{INTRODUÇÃO}

A Zona Costeira Brasileira é definida pelo decreto $\mathrm{n}^{\circ} 5.300 / 2004$, sendo caracterizada enquanto o espaço geográfico onde ocorre a interação do ar, do mar e da terra, incluindo recursos renováveis ou não, presentes nessa porção do território. Perante isso a Zona Costeira abrange uma faixa marítima e uma faixa terrestre, as quais apresentam os seguintes limites: a faixa marítima enquanto o espaço que se estende por doze milhas náuticas, medido a partir das linhas de base (totalidade do mar territorial); e, a faixa terrestre enquanto o espaço delimitado pelos limites dos Municípios que sofrem influência direta dos fenômenos ocorrentes na zona costeira.

Englobando 395 municípios, um litoral com mais de 8.500km de extensão que perpassa por 17 estados, a Zona Costeira Brasileira foi historicamente área prioritária de ocupação e no estabelecimento de nucleações urbanas, compreendendo atualmente grandes regiões metropolitanas como as do Rio de Janeiro, Salvador, Recife e Fortaleza, e concentrando mais de $23 \%$ da população total do país, segundo dados do IBGE (2000). 
Muito do patrimônio natural presente na Zona Costeira foi perdido nesses mais de cinco séculos do descobrimento do país pelos portugueses, por meio da devastação de enormes áreas de floresta atlântica, ocupação de campo de dunas e estuários pela expansão urbana, uso de planícies flúviomarinhas para o desenvolvimento de atividades econômicas, entre outros. As medidas e os estudos realizados nas últimas décadas, mediante ao crescimento da importância ambiental nos contextos político, científico e do senso comum, tomam como base principalmente a componente biótica da paisagem, em especial áreas remanescentes de Mata Atlântica no litoral leste. Tal fato é devido, principalmente, à facilidade de se compreender a importância dos elementos biológicos no contexto ambiental.

Porém, além de se entender a biodiversidade costeira é necessário estimular estudos sobre a vertente abiótica, ou seja, sobre a geodiversidade que é definida por Gray (2008, p. 31, tradução nossa) enquanto "a variedade natural (diversidade) de características geológicas (rochas, minerais, fósseis), geomorfológicas (relevos, processos) e de solos". Dessa forma a geodiversidade deve ser encara enquanto a base de sustentação para toda forma de vida, sendo a ela adquirida uma enorme gama de valores (intrínseco, econômico, funcional, científico, entre outros).

Diante disso o presente artigo tem como objetivo discutir os elementos da geodiversidade presente na Zona Costeira Brasileira que adquirem caráter excepcional e são classificados como geossítios pela Comissão Brasileira de Sítios Geológicos e Paleobiológicos em seus três livros (volumes) disponibilizados ao público. Pretende-se elencar as características gerais desses geossítios, bem como os aspectos referentes a conservação e nível de proteção legal, propiciando assim uma leitura clara e sucinta sobre o patrimônio geológico costeiro brasileiro.

\section{METODOLOGIA}

A metodologia utilizada para a realização do presente trabalho é baseada em busca, tratamento e discussão de dados e informações oriundas de levantamento bibliográfico, em livros, artigos e decretos de lei, sobre os temas abordados, os quais são compreendidos pela Comissão Brasileira de Sítios Geológicos e Paleobiológicos (SIGEP), definições e classificação de Zona Costeira em âmbito nacional (bem como suas características gerais), Geodiversidade, Patrimônio Geológico e Geoconservação.

Foi realizada uma análise nos três livros publicados pela SIGEP que contemplam os sítios geológicos brasileiros com intuito de identificar os locais de relevância que se encontram dispostos na Zona Costeira Brasileira. 


\section{RESULTADOS E DISCUSSÃO}

A Comissão Brasileira de Sítios Geológicos e Paleobiológicos (SIGEP) configurava-se como o órgão responsável pela gerência do patrimônio geológico nacional. A comissão foi instituída no ano de 1997 pelo Departamento Nacional de Produção Mineral (DNPM), tendo sua base no Grupo de Trabalho de Sítios Geológicos e Paleobiológicos do Patrimônio Mundial, da Organização das Nações Unidas para Educação, Ciência e Cultura (UNESCO), da qual a DNPM já fazia parte desde o ano de 1993. A SIGEP durante o seu funcionamento contou com representantes de doze instituições dentre as quais o Instituto Brasileiro de Geografia e Estatística (IBGE), o Instituto Chico Mendes de Conservação da Biodiversidade (ICMBio), o Instituto do Patrimônio Histórico e Artístico Nacional (IPHAN), e a Sociedade Brasileira de Geologia (SBG).

Os principais objetivos da SIGEP eram o levantamento, a discrição e a divulgação de sítios geológicos. A divulgação era realizada por meio da disponibilização, por meio digital e/ou impresso, de artigos científicos bilíngues elaborados por especialistas que realizavam estudos na área do sítio cadastrado (alguns apresentam versão em linguagem para leigos, o que aumenta a sua utilização como meio de propagação do conhecimento científico referente às Ciências da Terra), assim como a confecção de livros e publicação de artigos em revistas e congressos científicos.

A SIGEP durante seu período de atuação publicou 116 geossítios, sendo as suas descrições em disponíveis no formato de capítulos de livro, destes 58 geossítios estão no primeiro volume do livro Sítios Geológicos e Paleontológicos do Brasil (SCHOBBENHAUS et al, 2002), 40 no segundo (WINGE et al, 2009) e 18 no terceiro (WINGE et al, 2013). Além dos sítios publicados a SIGEP conta com 49 propostas de geossítios aprovados (dos quais 11 estão localizados em municípios pertencentes a Zona Costeira Brasileira), mas que ainda não foram descritos sistematicamente como determina as orientações da Comissão (WINGE et al, 2013). A não publicação é devido a vários motivos, dentro os quais a não existência de autores confirmados para realizar a descrição do sítio geológico (situação de 32 dos 49 geossítios propostos) e a paralização da SIGEP no ano de 2012 devido problemas legais, como expõe o presidente Carlos Schobbenhaus

A Comissão Brasileira de Sítios Geológicos e Paleobiológicos - SIGEP, mesmo instituída e exercendo "de fato" as suas competências, não foi oficializada "de direito" no âmbito do Poder Público, o que lhe tira a capacidade de adotar medidas legais para a preservação dos geossítios. Pela importância alcançada na identificação de sítios do patrimônio geológico e paleontológico brasileiro e por representar o fórum mais adequado para o tratamento dessas questões, torna-se necessária a sua oficialização, que já vinha sendo demandada pelo próprio Ministério Público. (Trecho disponível em: http://sigep.cprm.gov.br, acesso em 17 de junho de 2016). 
Os geossítios propostos para a SIGEP seguiam categorias temáticas principais (Astroblema; Espeleológico; Estratigráfico; Geomorfológico; Hidrogeológico; História da Geologia, Mineração, Paleontologia; Ígneo; Marinho-submarino; Metamórfico; Metalogenético; Mineralógico; Paleoambiental; Paleontológico; Sedimentar; Tectonoestrutural; outros) e tendo como critérios:

(i) sua singularidade na representação de sua tipologia ou categoria; (ii) importância na caracterização de processos geológicos-chave regionais ou globais, períodos geológicos e registros expressivos na história evolutiva da Terra; (iii) expressão cênica; (iv) bom estado de conservação; (v) acesso viável; e (vi) existência de mecanismos ou possibilidade de criação de mecanismos que lhe assegure conservação e consequente aproveitamento. (MANSUR et al, 2013 b, p. 05)

Antes de discutir sobre o patrimônio geológico costeiro brasileiro descrito pela SIGEP é válido abordar o conceito de sítio geológico, ou como também é designado, geossítio. Segundo Brilha (2005, p. 52) os geossítios podem ser definidos enquanto a ocorrência de "um ou mais elementos da geodiversidade (...), bem delimitado geograficamente e que apresente valor singular do ponto de vista científico, pedagógico, cultural, turístico, ou outro". Os geossítios listados pela SIGEP apesar de apresentarem, em muitos casos, relevância histórica, cultural e/ou pedagógica, expõem no valor científico do local a sua principal justificativa de seleção.

Diante disso os geossítios elencados no presente trabalho correspondem a locais de elevada relevância científica, sendo locais fundamentais para a conservação e reprodução do conhecimento geológico brasileiro. Tornasse válido salientar também que os geossítios aqui listados estão inseridos no contexto dos municípios que compreendem a Zona Costeira brasileira (Brasil, 2004), não necessariamente estão localizados na linha de costa.

O primeiro volume publicado da SIGEP (SCHOBBENHAUS et al, 2002) conta com nove geossítios em zona costeira dos 58 descritos (Tabela 01), correspondendo assim a 15,52\% dos geossítios listados. Os geossítios estão dispostos em sete estados diferentes (Bahia, Espirito Santo, Pará, Pernambuco, Rio de Janeiro, Rio Grande do Norte e Santa Catarina) e inseridos em cinco categorias temáticas distintas (4 geossítios marinhos, 2 sedimentológicos, 1 geomorfológico, 1 paleoambiental, 1 paleontológico).

Dos geossítios listados no primeiro volume cinco estão inseridos em diferentes categorias de unidade de conservação/área preservação ambiental, sendo eles: Abrolhos, Arquipélago de Fernando de Noronha, Atol das Rocas, Ilha de Trindade e o Pão de Açúcar. Já os geossítios Complexo Lagunar Centro-Sul Catarinense, Costa do Descobrimento, Ilha de Fortaleza e Lagoa Salgada não apresentam qualquer proteção no âmbito legal, sendo a proposição de áreas de proteção um ação comum entre os pesquisadores/autores dos diversos escritos. 
Tabela 01. Geossítios Costeiros presentes no primeiro volume da SIGEP. Fonte: Elaborado pelo autor com base em SCHOBBENHAUS et al (2002).

\begin{tabular}{|c|c|c|c|}
\hline Geossítio & Categoria & Autores & Características Gerais \\
\hline $\begin{array}{l}\text { Abrolhos - } \\
\text { BA }\end{array}$ & Marinho & $\begin{array}{l}\text { - Zelinda Margarida A. } \\
\text { N. Leão }\end{array}$ & $\begin{array}{l}\text { Maior e mais rico recife de corais do Brasil e de todo o } \\
\text { Atlântico Sul. Ótimo exemplo da interação geodiversidade- } \\
\text { biodiversidade. Apresenta diferenças na fauna coralina em } \\
\text { relação aos demais recifes de corais do Atlântico devido sua } \\
\text { forma de crescimento e morfologia. }\end{array}$ \\
\hline $\begin{array}{l}\text { Arquipélago } \\
\text { de Fernando } \\
\text { de Noronha - } \\
\text { PE }\end{array}$ & Marinho & $\begin{array}{l}\text { - Fernando F.M. de } \\
\text { Almeida }\end{array}$ & $\begin{array}{l}\text { Pequeno arquipélago vulcânico constituído de rochas do alto } \\
\text { de um monte vulcânico que faz parte da cadeia homônima } \\
\text { desenvolvida numa zona de fraturas oceânicas orientadas a E- } \\
\text { W. Local de grande beleza cênica. }\end{array}$ \\
\hline $\begin{array}{c}\text { Atol das } \\
\text { Rocas - RN }\end{array}$ & Marinho & - Ruy K. P. Kikuchi & $\begin{array}{l}\text { Primeira Unidade de Conservação marinha do Brasil, } \\
\text { representa um recife elíptico com cerca de } 7,5 \mathrm{~km}^{2} \text {, apresenta } \\
\text { intenso crescimento de algas coralinas e presença de arenitos } \\
\text { de praia que remontam variações do nível do mar. }\end{array}$ \\
\hline $\begin{array}{l}\text { Complexo } \\
\text { lagunar } \\
\text { Centro-Sul } \\
\text { Catarinense - } \\
\text { SC } \\
\end{array}$ & Sedimentológico & $\begin{array}{l}\text { - Paulo César F. } \\
\text { Giannini }\end{array}$ & $\begin{array}{l}\text { Adquire importância sedimentológica devido ao complexo } \\
\text { sistema deposicional composto por lagunas, barras, barreiras, } \\
\text { planície costeira, dunas quaternárias. É um importante sítio } \\
\text { arqueológico e histórico devido a concentração de sambaquis e } \\
\text { por ser cenário da revolução dos Farrapos. }\end{array}$ \\
\hline $\begin{array}{l}\text { Costa do } \\
\text { Descobri- } \\
\text { mento - BA }\end{array}$ & Sedimentológico & $\begin{array}{l}\text { - José Maria L. } \\
\text { Dominguez } \\
\text { - Louis Martin } \\
\text { - Abílio Carlos S. } \\
\text { Bittencourt }\end{array}$ & $\begin{array}{l}\text { Paisagem com profundo significado para a memória nacional } \\
\text { por compreender o trecho da costa brasileira primeiro visitado } \\
\text { pelos portugueses. Marcado pela presença de Tabuleiros } \\
\text { costeiros e depósitos quaternários que demonstram variações } \\
\text { no nível do mar. }\end{array}$ \\
\hline $\begin{array}{l}\text { Ilha de } \\
\text { Fortaleza - } \\
\text { PA }\end{array}$ & Paleontológico & $\begin{array}{l}\text { - Vladimir A. Távora } \\
\text { - Antônio Carlos S. } \\
\text { Fernandes } \\
\text { - Cândido S. Ferreira }\end{array}$ & $\begin{array}{l}\text { Rico conteúdo fossilífero que compreende uma das mais } \\
\text { expressivas ocorrências do Cenozoico Marinho do Brasil. } \\
\text { Seção tipo da Formação Piranhas e local com diversidade de } \\
\text { estudos científicos desde do século XIX, o que reafirma sua } \\
\text { relevância também no campo da história da geologia. }\end{array}$ \\
\hline $\begin{array}{l}\text { Ilha de } \\
\text { Trindade - } \\
\quad \text { ES }\end{array}$ & Marinho & $\begin{array}{l}\text { - Fernando F. M. } \\
\text { Almeida }\end{array}$ & $\begin{array}{l}\text { Pequena Ilha vulcânica a } 1.140 \mathrm{~km} \text { da costa, configurasse } \\
\text { como o cimo erodido de uma grande montanha vulcânica que } \\
\text { faz parte de um lineamento de montes vulcânicos submarinos. } \\
\text { Com relevo extremamente acidentado é possível parte de um } \\
\text { cone vulcânico na paisagem. }\end{array}$ \\
\hline $\begin{array}{c}\text { Lagoa } \\
\text { Salgada }- \text { RJ }\end{array}$ & Paleoambiental & $\begin{array}{l}\text { - Narendra K. } \\
\text { Srivastava }\end{array}$ & $\begin{array}{l}\text { Abriga a única ocorrência de estromatólitos recentes do Brasil. } \\
\text { Sendo composto por estromatólitos carbonáticos colunares, } \\
\text { domais, estratiformes, trombólitos e encólicos de idade } \\
\text { holocênicas, com idade máxima de } 3780+/-170 \text { anos AP. As } \\
\text { investigações apontam } 19 \text { espécies de cianofíceas. }\end{array}$ \\
\hline $\begin{array}{c}\text { Pão de } \\
\text { Açúcar - RJ }\end{array}$ & Geomorfológico & $\begin{array}{l}\text { - Luiz Carlos da Silva } \\
\text { - Antônio José L. A. } \\
\text { Ramos }\end{array}$ & $\begin{array}{l}\text { Corpo granítico pertencente a Suíte Rio de Janeiro, } \\
\text { representando um marco da amalgação final da Gondwana. Um } \\
\text { dos principais cartões postais brasileiros com elevada } \\
\text { importância turística e para a história da geologia brasileira. }\end{array}$ \\
\hline
\end{tabular}

Quando analisado nas descrições disponibilizadas o índice de degradação e/ou pressão por atividades antrópicas é possível distinguir que cinco dos geossítios listados não se apresentam degradados ou sobre forte pressão, sendo eles, a Ilha de Fortaleza, que apesar de não ser uma área protegida está inserida num local com baixa densidade demográfica, Arquipélago de Fernando de Noronha, Atol das Rocas, Ilha de Trindade e o Pão de Açúcar, os quais se apresentam como áreas protegidas. Três geossítios se apresentam parcialmente degradados ou sobre forte pressão antrópica, sendo eles, o Complexo Lagunar Centro-Sul Catarinense e Costa do Descobrimento, que devido a elevada dimensão apresentam áreas bem conservadas em contraste com outras ocupadas por 
urbanização e atividades agrícolas, e o geossítio de Abrolhos que, apesar de ser uma área protegida legalmente, devido sua dimensão apresenta áreas que não são englobadas e também por fatores indiretos como poluição que ocorre na costa, mas atinge as feições.

Por fim, o sitio geológico da Lagoa Salgada se apresenta sobre forte pressão antrópica o que pode resultar em sua degradação completa, já que área configurasse enquanto uma "região altamente poluída, pois ao redor dessa lagoa são situados sítios agropecuários e de lazer que, muitas vezes, utilizam agrotóxicos e outros produtos nocivos, criando situações altamente perigosas para alterações do ambiente hidroquímico da lagoa" (SRIVASTA, 2002, p. 206), diante disso a autora salienta a necessidade urgente de ações como a desapropriação e isolamento de áreas ao redor da lagoa para que não se perca esse importante patrimônio geológico que é composto por estromatólitos, os quais são sensíveis a ação antrópica.

O segundo volume publicado da SIGEP (WINGE et al, 2009) conta com nove geossítios em zona costeira dos 40 inventariados (Tabela 02), o que corresponde a 22,5\% dos geossítios descritos. Os geossítios estão dispostos em quatro estados diferentes (Ceará, Pernambuco, Rio de Janeiro e Rio Grande do Sul) e inseridos em seis categorias temáticas (2 geossítios geomorfológicos, 2 ígneos, 2 paleontológicos, 1 marinho, 1 paleoambiental e 1 tectônico).

Cinco dos geossítios listados no segundo volume estão inseridos em diferentes categorias de unidade de conservação/área preservação ambiental. O Arquipélago de São Pedro e São Paulo e as Falésias da Praia de Ponta Grossa são Áreas de Proteção Ambiental (APA), a Bacia São José de Itaboraí e o Granito do Cabo de Santo Agostinho estão inseridos em parques municipais, os Eolianitos de Flecheiras-Mundaú compreendem Área de Preservação Permanente (APP) de acordo legislação especifica do estado do Ceará. Os demais geossítios (Barrancas Fossilíferas do Arroio Chuí, Dunas de Albardão, Estratos Calcários da Pedreira Poty e o Ignimbrito do Engenho Saco) não apresentam quaisquer legislação especifica para sua proteção.

Quando ao índice de degradação e/ou pressão por atividades antrópicas percebesse que os cinco geossítios em áreas de proteção legalmente definidas não se apresentam degradados ou sobre forte pressão mesmo quando apresentam elevada fragilidade natural como é o caso dos Eolianitos de Flexeiras-Mundaú e das Falésias da Praia de Ponta Grossa. Dois geossítios se apresentam parcialmente degradados e sobre pressão antrópica. O primeiro é as Barrancas Fossilíferas do Arrio Chuí, devido ao fato do afloramento perpassar por diversas propriedades rurais particulares, porém os autores salientam que a população local têm consciência da importância dos fósseis e acabam por guardar os exemplares em suas residências ou entregam no museu presente em Santa Vitória do Palmar (LOPES et al, 2009), o segundo as Dunas de Albardão, o qual se configura por um geossítio 
de grandes dimensões sendo a sua área interior de difícil acesso, porém nos seus limites norte e sul tem se incentivado a instalação de fazendas de eucalipto.

Tabela 02. Geossítios Costeiros presentes no segundo volume da SIGEP. Fonte: Elaborado pelo autor com base em (WINGE et al, 2009).

\begin{tabular}{|c|c|c|c|}
\hline Geossítio & Categoria & Autores & Características Gerais \\
\hline $\begin{array}{l}\text { Arquipélago de } \\
\text { São Pedro e São } \\
\quad \text { Paulo - PE }\end{array}$ & Marinho & $\begin{array}{l}\text { - Thomas F. C. } \\
\text { Campos et. al. }\end{array}$ & $\begin{array}{l}\text { Menor arquipélago oceânico brasileiro, situa-se no meio do } \\
\text { Atlântico-Norte Equatorial distante } 1.010 \mathrm{~km} \text { da costa. } \\
\text { Diferente de outros arquipélagos oceânicos é formado por } \\
\text { rochas plutônicas e não por rochas vulcânicas. }\end{array}$ \\
\hline $\begin{array}{l}\text { Bacia São José } \\
\text { de Itaboraí - RJ }\end{array}$ & Paleontológico & $\begin{array}{l}\text { - Lílian P. } \\
\text { Bergqvist et. al. }\end{array}$ & $\begin{array}{l}\text { Bacia de idade paleogênica com cerca de apenas } 1 \mathrm{~km} 2 \text {, mas, } \\
\text { ricamente fossilífero. Contém os registros brasileiros mais } \\
\text { antigos de animais e vegetais continentais posteriores à } \\
\text { extinção dos dinossauros, } \\
\text { final do Cretáceo. Presença de artefatos que remetem a uma } \\
\text { sequencia tecnológica de pelo menos } 1 \text { Ma (Pleistoceno } \\
\text { médio). }\end{array}$ \\
\hline $\begin{array}{l}\text { Barrancas } \\
\text { Fossilíferas do } \\
\text { Arroio Chuí - } \\
\quad \text { RS }\end{array}$ & Paleontológico & $\begin{array}{l}\text { - Renato Lopes } \\
\text { et. al. }\end{array}$ & $\begin{array}{l}\text { Depósitos com fósseis de mamíferos extintos da megafauna de } \\
\text { idade Lujanense (120.000 anos A.P.). Os estudos dos depósitos } \\
\text { e fósseis contribuem para a reprodução da paleoecologia e do } \\
\text { paleoclima do sul do Brasil, bem como o entendimento dos } \\
\text { processos costeiros passados. }\end{array}$ \\
\hline $\begin{array}{c}\text { Dunas de } \\
\text { Albardão-RS }\end{array}$ & Geomorfológico & $\begin{array}{l}\text { - Renato P. } \\
\text { Lopes et. al. }\end{array}$ & $\begin{array}{l}\text { Extenso campo de dunas de grande beleza cênica, altura } \\
\text { expressiva e importância ambiental. Campo formado devido a } \\
\text { variação do nível do mar, em especial aos máximos } \\
\text { transgressivos. Habitat de grande biodiversidade, contendo } \\
\text { evidências arqueológicas da ocupação por paleo-índios }\end{array}$ \\
\hline $\begin{array}{l}\text { Eolianitos de } \\
\text { Flexeiras- } \\
\text { Mundaú - CE }\end{array}$ & Geomorfológico & $\begin{array}{l}\text { - Alexandre M. } \\
\text { Carvalho et. al. }\end{array}$ & $\begin{array}{l}\text { Campo de eolianitos, os quais constituem uma unidade } \\
\text { geológica holocênica rara no litoral brasileiro. Fornece } \\
\text { importantes informações sobre a dinâmica eólica, as condições } \\
\text { climáticas e do ambiente costeiro existentes à época de sua } \\
\text { formação. }\end{array}$ \\
\hline $\begin{array}{l}\text { Estratos } \\
\text { Calcários da } \\
\text { Pedreira Poty } \\
\text { (Paulista) - PE }\end{array}$ & Paleoambiental & $\begin{array}{l}\text { - Gilberto A. } \\
\text { Albertão } \\
\text { - Paulo Pereira } \\
\text { M. Jr. }\end{array}$ & $\begin{array}{l}\text { Primeira localidade aflorante descrita na América do Sul como } \\
\text { uma sequência sedimentar completa através do limite entre os } \\
\text { períodos Cretáceo e Terciário (limite K-T). Apresenta } \\
\text { características única entre as bacias sedimentares brasileiras } \\
\text { descritas até o momento de publicação. }\end{array}$ \\
\hline $\begin{array}{l}\text { Falésias da Praia } \\
\text { de Ponta Grossa, } \\
\text { Icapuí - CE }\end{array}$ & Tectônico & $\begin{array}{l}\text { - Debora C. } \\
\text { Sousa et. al. }\end{array}$ & $\begin{array}{l}\text { Composto por falésias que mostram rochas de várias } \\
\text { formações geológicas. Na base ocorre uma unidade carbonática } \\
\text { correlacionada à Formação Jandaíra. Sobreposta está o Grupo } \\
\text { Barreiras, o qual ocorre em dois contextos estruturais, com } \\
\text { estratos horizontalizados e não deformados ou com camadas } \\
\text { basculadas e afetadas por deformação tectônica. }\end{array}$ \\
\hline $\begin{array}{l}\text { Granito do Cabo } \\
\text { de Santo } \\
\text { Agostinho-PE }\end{array}$ & Ígneo & $\begin{array}{l}\text { - Marcos A. L. } \\
\text { Nascimento } \\
\text { - Zorano Sérgio } \\
\text { de Souza }\end{array}$ & $\begin{array}{l}\text { Corpo granítico semicircular com } 4 \mathrm{~km}^{2} \text { de área aflorante, } \\
\text { representando um raro exemplo de granito com idade cretácea } \\
\text { do Brasil }(102 \pm 1 \mathrm{Ma} \text { ). O local ainda apresenta relevância } \\
\text { histórica que remete ao período do descobrimento e a presença } \\
\text { de relevante patrimônio arquitetônico. }\end{array}$ \\
\hline $\begin{array}{l}\text { Ignimbrito do } \\
\text { Engenho Saco, } \\
\text { Ipojuca - PE }\end{array}$ & Ígneo & $\begin{array}{l}\text { - Marcos A. L. } \\
\text { Nascimento et al }\end{array}$ & $\begin{array}{l}\text { Volumoso magmatismo de idade cretácea, incluindo rochas } \\
\text { vulcânicas e subvulcânicas. Extensos derrames piroclásticos } \\
\text { estão representados por brechas piroclásticas, tufos e lapilitos. }\end{array}$ \\
\hline
\end{tabular}

Por fim, os geossítios Estratos Calcários da Pedreira Poty e o Ignimbrito do Engenho Saco se apresentam com elevado índice de degradação e forte pressão por atividades antrópicas. Os dois estão localizados em áreas de mineração, sendo necessário a instituição de medidas de proteção para não resultar na descaracterização ou perda total dos elementos de importância geológica. 
O terceiro volume publicado da SIGEP (WINGE et al, 2013) conta com apenas 18 geossítios descritos sendo que três estão localizados na zona costeira (Tabela 03), o que corresponde a 16,7\% dos geossítios inventariados. Os geossítios estão dispostos em três estados diferentes (Ceará, Pernambuco e Rio de Janeiro) e inseridos em três categorias temáticas distintas (Geomorfológico, História da Geologia e Sedimentológico).

Tabela 03. Geossítios Costeiros presentes no terceiro volume da SIGEP. Fonte: Elaborado pelo autor com base em (WINGE et al, 2013).

\begin{tabular}{|c|c|c|c|}
\hline Geossítio & Categoria & Autores & Características Gerais \\
\hline $\begin{array}{l}\text { Arrecife, a } \\
\text { Calçada do } \\
\text { mar de } \\
\text { Recife - PE }\end{array}$ & Sedimentológico & $\begin{array}{l}\text { - Alcina M. F. } \\
\text { Barreto et. al. }\end{array}$ & $\begin{array}{l}\text { Recife rochoso formado por areias e cascalhos depositados em } \\
\text { zona de intermaré e posteriormente cimentados por carbonato de } \\
\text { cálcio. Elemento paleoambiental por refletir nível relativo do } \\
\text { mar mais alto do que o atual durante o Holoceno. Elemento } \\
\text { geológico relevante para o estabelecimento da cidade de Recife. }\end{array}$ \\
\hline $\begin{array}{l}\text { Beachrocks } \\
\text { de Jaconé - } \\
\text { RJ }\end{array}$ & $\begin{array}{l}\text { História da } \\
\text { Geologia }\end{array}$ & $\begin{array}{c}\text { - Kátia L. Mansur } \\
\text { et. al. }\end{array}$ & $\begin{array}{l}\text { Rochas praias (beachrocks) com mais de } 1 \mathrm{~km} \text { de extensão } \\
\text { mapeadas primeiramente por Charles Darwin em } 1832 . \\
\text { Apresenta importante registro arqueológico devido a presença } \\
\text { de sambaquis e diversos estudos realizados. }\end{array}$ \\
\hline $\begin{array}{l}\text { Ponta de } \\
\text { Jericoacoara } \\
\text {-CE }\end{array}$ & Geomorfológico & $\begin{array}{c}\text { - Kátia de Julio et } \\
\text { al }\end{array}$ & $\begin{array}{l}\text { Promontório composto por afloramento de rochas } \\
\text { neoproterozoicas pouco comum no litoral nordestino, belas } \\
\text { feições geomorfológicas e arenitos de praia, conjunto de feições } \\
\text { que auxilia na entendimento da evolução geológica da região. }\end{array}$ \\
\hline
\end{tabular}

O geossítio Ponta de Jericoacoara está inserido em uma Unidade de Conservação de Proteção Integral, sendo ela o Parque Nacional de Jericoacoara, diante disso seus elementos apresentam um bom estado de conservação e as ações antrópicas no seu entorno são controladas por um plano de manejo. O geossítio Beachrocks de Jaconé se encontra em ótimo estado de conservação devido a impossibilidade legal de construção na área já que se trata de uma zona de APP (Área de Preservação Permanente), porém os autores salientam possíveis projetos de construção civil (estaleiros, espigões e atracadores) em formulação que podem modificar a dinâmica costeira da local e interferir diretamente e indiretamente no geossítio (MANSUR et al, 2013 a). O geossítio Arrecife não apresenta qualquer proteção no âmbito legal, apesar de ainda apresentar um bom estado de preservação a sua localização, em meio a região metropolitana de Recife-PE com aproximadamente quatro milhões de habitantes, faz com que o mesmo esteja sobre perigo iminente, sendo necessário a instituição de ações de educação ambiental para conscientizar a população que tem acesso aos arrecifes, principalmente nas praias de Boa Viagem e Pina, a importância ambiental que os mesmos apresentam, sendo a instalação de painéis explicativos-interpretativos uma proposta sugerida pelos autores (BARRETO et al, 2013).

Como síntese observou-se que nos três volumes publicados pela SIGEP estão presentes 21 geossítios na Zona Costeira Brasileira, o que corresponde a 18,1\% do total de sítios publicados. A diversidade é dada pelo fato dos mesmos pertencerem a oito categorias temáticas distintas, sendo 
cinco geossítios marinhos (23,8\% do total), quatro geossítios geomorfológicos (19,06\% do total), três geossítios paleontológicos e outros três sedimentológicos (14,29\% do total para cada categoria), dois geossítios paleoambientais e outros dois ígneos $(9,52 \%$ do total para cada categoria) e um geossítio referente a história da geologia e outro tectônico (4,76\% do total para cada categoria).

Dos geossítios costeiro doze estão inseridos em áreas com algum regime de proteção legal, o que corresponde a 57,14\% do total. Quanto ao nível de degradação e potencial de alteração por ação antrópica três geossítios (14,29\% do total) se encontram em estágio que requer preocupação enquanto a sua manutenção, bem como a instituição de medidas mitigadoras e de geoconservação, outros seis geossítios $(28,57 \%$ do total) se apresentam parcialmente atingidos por alterações em sua dinâmica e características originais o que faz necessário o incentivo de medidas de educação ambiental que conscientizem a população. Os doze demais geossítios $(57,14 \%$ do total) se apresentam em bom estágio de conservação o que se configura enquanto uma supressa mediante ao elevado índice de ocupação e degradação da Zona Costeira brasileira.

Por fim, tornasse válido salientar a importância que a Comissão Brasileira de Sítios Geológicos e Paleobiológicos apresentou (e ainda apresenta) para o desenvolvimento dos estudos ligados às temáticas da Geodiversidade, Patrimônio Geológico e Geoconservação, bem como na promoção de educação e consciência ambiental por meio da difusão de conhecimento sobre os componentes abióticos da paisagem brasileira, sempre enfatizando a relevância que esses apresentam.

\section{CONSIDERAÇÕES FINAIS}

Com a realização do presente trabalho percebesse a importância e diversidade dos geossítios presentes na Zona Costeira Brasileira, sendo a Comissão Brasileira de Sítios Geológicos e Paleobiológicos um importante meio de divulgação e valorização desses espaços. A metodologia aplicada, baseada numa análise de dados pré-existente complementada por uma discussão teórica, se mostrou válida já que foi possível observar o panorama geral da atuação situação dos geossítios costeiros. Torna-se válido o incentivo de pesquisas como a aqui apresentada em diferentes unidades geoambientais e delimitações políticas no intuito de facilitar o entendimento e reunir de pormenorizada as informações.

\section{REFERÊNCIAS}

BARRETO, A. M. F.; ASSIS, H. M. B.; BEZERRA, F. H. R.; SUGUIO, K.. Arrecifes, a Calçada do Mar de Recife, PE: Importante registro holocênico de nível relativo do mar acima do atual. In

Sítios Geológicos e Paleontológicos do Brasil. v. 3. Brasília: CPRM, 2013. 330p. 
BRASIL. Decreto $n^{\circ} 5.300$ de 7 de dezembro de 2004. Regulamenta a Lei $\mathrm{n}^{\circ}$ 7.661, de 16 de maio de 1988, que institui o Plano Nacional de Gerenciamento Costeiro (PNGC). Disponível em: http://www.planalto.gov.br/ccivil_03/_ato2004-2006/2004/decreto/D5300.htm acesso 17/06/2016.

BRILHA, J. Património Geológico e Geoconservação: A Conservação da Natureza na sua Vertente Geológica. Braga: Palimage Editores, 2005.

GRAY, M. Geodiversity: the origin and evolution of a paradigm. In: BUREK, C. V.; PROSSER, C. D. The history of Geoconservation. London: The Geological Society, Special Publications, 2008. p. $31-36$.

LOPES, R. P.; BUCHMANN,F. S. C. ; CARON, F. ; ITUSARRY, M. E. G. S.. Barrancas Fossilíferas do Arroio Chuí, RS: Importante megafauna pleistocênica no extremo sul do Brasil. In Sítios Geológicos e Paleontológicos do Brasil. v. 2. Brasília: CPRM, 2009. 515p

MANSUR, K. L.; RAMOS, R. R. C. ; FURUKAWA, G. G.. Beachrock de Jaconé, RJ: Uma pedra no caminho de Darwin. In Sítios Geológicos e Paleontológicos do Brasil. v. 3. Brasília: CPRM, 2013 a. 330p.

MANSUR, K. L. et al.. Iniciativas institucionais de valorização do patrimônio geológico do Brasil.

Boletem Paranaense de Geociências, v. 70. Curitiba: 2013 b.

SRIVASTAVA, N. K. Lagoa Salgada, RJ: Estromatólitos recentes. In Sítios Geológicos e Paleontológicos do Brasil. v. 1. Brasília: CPRM, 2002. 540p.

SCHOBBENHAUS, C.; CAMPOS, D.A.; QUEIROZ, E.T.; WINGE, M.; BERBERT-BORN, M.L.C.. Sítios Geológicos e Paleontológicos do Brasil. v. 1. Brasília: CPRM, 2002. 540p.

WINGE, M.; SCHOBBENHAUS, C.; SOUZA, C.R.G.; FERNADES, A.C.S.; QUEIROZ, E.T.; BERbERT-BORN, M.; CAMPOS, D. A.. Sítios Geológicos e Paleontológicos do Brasil. v. 2. Brasília: CPRM, 2009. 515p

WINGE, M.; SCHOBBENHAUS, C.; SOUZA, C.R.G.; FERNADES, A.C.S.; BERBERT-BORN, M.; SAlUM FILHO, W.; QUEIROZ, E.T.. Sítios Geológicos e Paleontológicos do Brasil. v. 3. Brasília: CPRM, 2013. 330p.

Recebido em: 14/08/2016

Aceito para publicação em: 01/10/2016 